\title{
Social Construction of Dependence in Elderly Men in Chile
}

\author{
Paulina Osorio-Parraguez ${ }^{1 *}$, Andrés G. Seguel1,2 \\ ${ }^{1}$ Department of Anthropology, University of Chile, Santiago, Chile \\ ${ }^{2}$ Department of Social Psychology, Universitat Autónoma de Barcelona, Barcelona, Spain \\ Email: posorio@uchile.cl
}

Received 26 February 2014; accepted 29 March 2014; accepted 7 April 2014

Copyright (C) 2014 by authors and Scientific Research Publishing Inc.

This work is licensed under the Creative Commons Attribution International License (CC BY). http://creativecommons.org/licenses/by/4.0/

(c) (i) Open Access

\begin{abstract}
Based on a qualitative research restricted to aging processes in Chile, the paper presents the experience and significance of dependence in elderly men and how it is related with the social construction of old age. It is important to know how the identity of aging is configured when facing such a significant biographical and social landmark as the loss of functionality in later life. When analyzing the social construction of dependence in elderly men, three aspects of that configuration stand out: first, the way in which they understand and signify their situations of illness, physical problems, disability, and evaluation of their health; second, the characteristics of the social significant contexts in which disability or physical problems become evident; and third, the actions, roles or activities that they perform in those contexts, which are valued differently according to the experiences of dependence or autonomy. Dependence in elderly men does not appear as a static condition, but rather as a passage from physical-biological conditioners to the social context in which their everyday actions take place. So the agency of the dependence, its construction, experience and significance is the understanding of the social phenomenon of old age.
\end{abstract}

\section{Keywords}

Dependence, Health, Aging, Elderly Men, Chile

\section{Introduction}

At present, Chile is one of the four most aged countries in Latin America, with a population of $12.1 \%$ aged 60 years or more [1]. Due to the progressive increase of life expectancy and the new passages within this last stage of the course of life, older people are becoming a differentiated age group, with their own cultural characteristics,

"Corresponding author. 
interests and social demands [2]. In view of these demographic circumstances, it can be foreseen that the greater longevity in the middle range will imply that dependence in old age will be one of its structural characteristics.

According to the results of the Estudio Nacional de la Dependencia en las Personas Mayores, (National Study of Dependence in the Elderly) EDPM 2009, 24.1\% of Chilean old adults have some degree of dependence (the figure for the Metropolitana Region is $21.1 \%$ ), and the dependence and its seriousness increase as age increases. It is seen that after 75 years serious dependence constitutes the greater proportion of total dependence, reaching figures higher than $30 \%$ in those older than 80 years [3]. It also shows that dependence is not only associated with loss of physical functionality; at the cognitive level, $35.2 \%$ of dependent elderly people present cognitive deterioration, indicating that the prevalence increases significantly with age, i.e., after 75 years. If for the total sample it was $8.5 \%$, for those older than 85 years it was higher than $40 \%$. Casado and López [4] suggest that there is a close relation between dependence and age when they state that "the percentage of individuals that undergo limitations in their functional ability increases as population cohorts of higher age are considered".

As age advances, the possibility of having greater difficulties in carrying out some daily activities autonomously increases, which may be due to two non-exclusive reasons. The first one is related to what Villa and Rivadeneira [5] describe as a natural physiological process that takes place gradually in people. The aging process brings about a number of changes in people's life, among them a decrease of vital functions determined by the progressive loss of structures and physical functions [6]. The second has to do with the propensity to chronic diseases, because in old age a number of body sequels that limit the abilities, adaptation and interaction functions in the aged persons with their biological, physical, psychological and social media would be appearing [7]. These diseases or deficiency contexts will cause the appearance of dependence situations also derived from a series of past socio-biographic scenarios such as malnutrition, social alienation, and poor work practices, among others. That is how throughout their lives the subjects undergo a number of socio-individual situations which, by interacting with given health conditions during old age, can generate and construct states of dependence in them. The gaps that exist between the abilities of the people, the demands of the environment, and the requirements of the context to carry out the activities, roles or social tasks would configure the framework for disability and dependence.

Dependence in demographic and biomedical crossing arises as a process that starts with the appearance of some altered health conditions in their functions and/or body structures (deficiencies). This deficit as a consequence of a disease or deterioration during the aging process generates limitations for carrying out some activities, with the appearance of significant barriers or hindrances in the biographic experience of elderly men. Dependence on social and biographic crossing is presented to the subjects as belonging to diverse life situations and does not have to be always the same in the history of people, so factors of context, both environmental (house, quarter, services) and personal (gender, education, widowhood condition) will affect its characteristics. In the case of widowed elderly persons, demographic analysis has shown that for various social contexts they would present greater health deterioration, thereby increasing the probability of being dependent, and higher mortality than married persons, and this is particularly true in the case of men [8].

Dependence as a concept has been defined in various disciplines and especially by gerontology, from which a number of approaches take into consideration this particular situation of the aging subjects, which is generating in them the need of help for the action. At times, the dependence situation may not appear, even though an old age has been reached, due to the existence of a number of sociocultural and socioenvironmental variables that can condition the appearance and development of its triggering factors. We can also find culturally generated dependences that have rarely been part of the classical theorizations of the medical viewpoints [9], which are multiple forms of dependence inspired in social constructions that are continually remodeled by the people and the communities [10].

According to the existing demographic and biomedical literature, it is possible to establish a link between the factors of age, physical function and social action with the purpose of considering dependence not only as a condition inherent to the people, but also as a systemic and complex dimension that involves other factors (social, contextual, biographic, environmental). From this perspective, the health condition would appear only as a starting point. Also, the biological declination typical of old age does not become evident in an isolated way, but rather as it interacts with the physical and social setting it brings about a number of experiences that give it sociocultural content and meanings [11]-[13]. Because of this, it is necessary to understand the dependence/autonomy relation in direct connection with the environmental changes and with the aging experience of the men.

The results shown below go more deeply into these relations by evaluating how elderly men perceive and in- 
terpret their degrees of dependence. The results extracted from the research started with an aged subject that has some physical or cognitive problems. At this point the idea of dependence as a passage among the physical-biological problems (disability) and a social-environmental context in the aged man exists.

Following this argument, making a conceptual description of the dependence situation of elderly men requires describing the characteristics of the aging process and how it can or cannot generate dependence-triggering situations. This passage will decant into formulas and logics for managing (agency) their autonomy/dependence by the aged.

\section{Materials and Methods}

The results that are presented correspond to a study that used qualitative information production methods to get to know the configuration of dependence in old age. The technique used was that of in-depth interviews of a biographic type. Also, accounts of life, work, conjugal, and widowhood trajectories were made. The analysis of personal histories [14] has provided knowledge of the way in which the narrators signify the dependence and assume the individual, family and social transitions and changes that it brings about in the aging process.

The research followed the orientations of a theoretical and intentional sampling, and the sample was based on the selection of subjects according to their structural characteristics. It was composed of retired, widowed people older than 60 years. The dependence was described and signified by those interviewed from the recognition of their limitation, barriers and/or need for help. In spite of the existence of a biological origin, the description of the dependence was also subject to factors of a social, biographic and environmental-contextual kind, which conditioned the appearance and development of the triggering factors of the dependence. For the initial analysis, the corpus was segmented into texts (citations) according to the construction of defined previously codes and by means of emergent coding from the empirical information. Qualitative categorical content analysis and inductive discourse analysis were performed.

\section{Results}

In the first part of the results the way in which elderly men understand and signify their disease situation, physical problems, disability and evaluation of their health is analyzed with the purpose of knowing the aspects that are deemed most important when thinking of performance in their social context. The second part presents the descriptions of the significant social contexts in which the disabilities or physical problems become evident. Finally, the third part identifies the actions, roles or activities that are developed in the contexts and which get different valuations in relation to the degree of dependence/autonomy. Therefore, the passage in the narrations from the physical-biological conditioners to the social context in which the actions take place will be described.

\subsection{Being Sick: "What's Killing Me Is Not Being Able to Walk"}

The loss of functionality is often related with physical-cognitive problems whose identificatory processes go through the medical context and the concern of the closest relatives. In this sense, the loss of functionality becomes a landmark that signals a before and after in the life of the aged, which is generally lived as an accident and is not always linked with an externality, since sometimes it is explained as part of the aging process.

The feelings of difficulties and loss of mobility during dependence lead to greater awareness of old age, but two positions are to be expected around them: 1) a certain acceptance of the process, or 2) a clear rebellion in the face of it. This limits the expectations around the possibility of autonomy, and leads to a different sort of life because of the fact of being or not being able to keep on carrying out some activities of daily life:

"The fact that one cannot hear well isolates you" (79 year old man).

Although in the discourses the loss of functional autonomy is recounted as a not necessarily linear process and in a single direction, showing advances and setbacks, elderly men identify clearly an event from which the dependence is triggered. This event or inflection point is often a health situation, even though it can also appear linked to the death of the spouse:

"What happened is the following: I had a serious accident, an accident after retiring, at the end of last year, and all of a sudden they found me in my apartment" (79 year old man). 
The biological situation that originates the dependence and puts in evidence the deterioration suffered by the aging men is mediatized by the interpretations of biomedical concepts as well as of popular medicine and/or alternative medicine. In this sense, three levels of interpretation can be established: 1) What the person lives through; 2) what can be interpreted from non allopathic medical knowledge, and 3) what the allopathic physician diagnoses:

"I take these medicines so the blood is well liquefied, liquid, because with the thrombosis it is sort of clogged, and cannot circulate well. It is stuck, otherwise I would be worse, because the thrombosis is stuck to the leg bone, so if I am operated, the doctor told me, there are possibilities of getting well and possibilities of getting worse" (88-year-old man).

It would seem that the first two interpretation levels are less felt and dramatic than that proposed by a physician. This may be due to the fact that the confirmation of the ailment with a medical diagnosis introduces a label and a probable outcome, but not so with the other levels, which are presented as not so specific and culturally less legitimated.

The perceptions around the physical deficiencies are considered separately from the cognitive faculties, but the latter are the ones most valued by them. The cognitive faculties are valued and allow understanding the worn-out body with little functionality:

“... the most serious consequences that I have is the memory which is bad and that is why I am attending the Municipal workshops, because there they offer courses for memory" (79-year-old man).

On this point a very clear distinction is produced between cognition and the body, and also of parts of the body with respect to the total, causing a fragmented vision of oneself in the aging process.

\subsection{The Social Context: "I Am Already Staying Behind. That' Was the Worst for Me"}

The context elements highlighted by the elderly men in the narrations are linked mainly with the family and quarter environment. The company of the children and the neighbors, and the death of many of their contemporaries, are recognized, and this gradually reduces their friendship networks and many times causes the reduction of social and leisure activities. Although the family is seen as a contention and help space, reference is also made to the distance that sometimes there is, which generates the experience of living in loneliness, in the case of widowers:

"Thanks God, I do not depend on others, except for breakfast, in the morning, which I receive with pleasure, because in the morning it is getting very cold" (79-year-old man).

The context is finally composed of two references. On the one hand, the meso-environment: friends and neighborhood residents, and on the other hand the endo-environment: family, sons and daughters [15].

When the dependent elderly can carry out some activities that do not benefit those who live together with them or benefit the community, their dependence is reduced or limited. In this sense, the social context can contribute a mediation that is a facilitator and opens spaces as agency of autonomy.

\subsection{The Actions: "I Don’t Do Almost Anything Anymore. It's Because at This Age!"}

The situation generated by a dependence in which implements for moving around or the help of others are required, is lived as a barrier for getting along in daily life.

Although the central issue is the difficulty or problems for moving, the social action linked to it acquire greater importance, whether it cannot be carried out or it is carried out with modifications:

"I have no problems for driving, and I like to drive! Long trips, I go to the countryside or to the coast. But now my daughter has told me to never travel alone, to travel always with someone who can drive” (79year-old man).

The difficulties generated by the barriers are compensated many times by the help of third parties, who can be relatives, friends or neighbors. In most cases it is the sons and daughters who provide help. This help can be linked with mobility, carrying out daily chores, or matters that involve moving around town: 
"This thing of being immobilized, one gets used, I know what it is like, disassembling this [wheelchair] and there I climb over the side of the bed, they have to fix the chair so that I can get there and climb” (86 year old man).

“No, I don't go anywhere alone. My son drives me in the car, and when I go out it is to go to the hospital, otherwise nowhere; I'm always here, only at home” (86-year-old man).

This help to carry out some specified social actions is sometimes valued and sometimes resisted, and at times it can have a direct link with the psychological conditions.

Another dimension in which action acquires meaning for elderly men is the realm of decision making. Their decisions are made in a dialog with those who take care of or live with them; in the case of the interviewed widowed men it was mainly a daughter.

Functionality and its loss are related, on the one hand, by the enumeration of those actions that can no longer be carried out, and on the other hand by those which, on the contrary, they do carry out, in spite of the physical situation in which they are and the context in which they perform daily. They are actions in the realm of the day-by-day, which are presented as a bastion of resistance in the face of the loss caused by the physical-biological deterioration and of what is imposed by the social construction of the age.

The confluence of age, aging and physical-biological problems seems to produce a priori a context of dependence, at least in its functional emphasis. However, we have observed that the idea of presupposed autonomy is rather a field in which activities, contexts, social links are managed, i.e., it puts forth, in anthropological terms, a cultural and symbolic construction space of dependence in old age.

\section{Conclusions}

The results presented here indicate that old age and aging are lived as a process in which transformations, in a context of continuity and changes, are a constant. Therefore, the losses undergone by elderly men are signified, in general, in an undramatic way and with an important component of conformism or naturalization of the process.

We propose to understand dependence, in the case of elderly persons, as a passage at whose starting point there are the psychic or physical problems, and which are signified as facilitators or barriers in their social actions. Stated in this way, as a passage, we find that dependence is not opposed to autonomy, and that the aged bring into play a logic to manage their degrees of autonomy.

The particularity acquired by the significance given to dependence as a constitutive element of old age is linked many times to the social role from which everyday life is experienced. The losses are then compensated by what this social and cultural context can be provided in terms of help and/or contention, with the consequences that can become or have a facilitating or hindering (barrier) effect to the aged person. Dependence would move, therefore, between physical independence and disability.

Considering the process of dependence of elderly men, the results of the research showed us a set of meanings and interpretations of how the different degrees of autonomy are managed, so that elderly people interpret their condition as dependents insofar as they conceive their disability as a facilitator or a barrier for performing their social actions. Therefore, dependence is not valued in itself, but in relation to a wider social and interacting context.

Dependence turns out to be a multidimensional concept that is linked to being or not being able to carry out some activities of daily life, giving it its objective character. But as we have seen, dependence is also subjective, self-observed and signified, in spite of its objective and measurable character.

The central question in this paper has been to ask for the meanings with which the passage between a deficiency and dependence in elderly men is constructed. In it we have stressed its relational character as well as the dependence/autonomy pair as a whole. From that it is concluded that dependence/autonomy is put in evidence by some situations linked with the experience of aging and the appearance of some physical-biological problems.

\section{Acknowledgements}

Work developed for Fondecyt project 1110110 "Procesos estructurales de la viudez en la construcción social del envejecimiento" ("Structural processes of widowhood in the social construction of aging"). The authors acknowledge with thanks the support of Julio Chica Valencia and Samuel Briones in writing this paper. 


\section{References}

[1] Instituto Nacional de Estadística (INE) (2007) Enfoque estadístico. Adulto Mayor en Chile. http://www.ine.cl

[2] Arber, S. and Ginn, J. (1995) Choice and Condtraint in the Retirement of Older Married Women. In: Arber, S. and Ginn, J. Eds., Connecting Gender \& Ageing. A Sociological Approach, Open University Press, Buckingham.

[3] Servicio Nacional del Adulto Mayor (2009) Estudio Nacional de la Dependencia en las Personas Mayores. SENAMA, Santiago.

[4] Casado, D. and López, G. (2001) Vejez, dependencia y cuidados de larga duración. Situación actual y perspectivas de Futuro. Colección Estudios Sociales No 6. Fundación La Caixa, Barcelona.

[5] Villa, M. and Rivadeneira, L. (1999) Encuentro Latinoamericano y Caribeño sobre las Personas de Edad. CELADE, Santiago.

[6] Manton, K.G. (1991) The Dynamics of Population Aging: Demography and Policy Analysis. The Milbank Quarterly, 69, 309-338. http://dx.doi.org/10.2307/3350207

[7] Chambres, L. (1983) Quality Assurance in Long-Term Care: Policy, Research and Measurement. OMS, Paris.

[8] Guilbault, C., Dal, L. and Poulain, M. (2007) Le veuvage et après. Gérontologie et Société, 121, 163-178. http://dx.doi.org/10.3917/gs.121.0163

[9] VV.AA. (2005) Libro Blanco de atención a la dependencia en España. Ministerio de Trabajo y Asuntos Sociales e IMSERSO, Madrid.

[10] Guillemard, A.M. (1993) Perspectivas europeas sobre las políticas de vejez. In: Moreno, L., Ed., Intercambio social y desarrollo del Bienestar, CSIC, Madrid.

[11] Minkler, M. (1996) Critical Perspectives on Ageing. New Challenges for Gerontology Ageing and Society, 16, 467487.

[12] Phillipson, C. (1998) Reconstructing Old Age. New Agendas in Social Theory and Practice. Sage, London.

[13] Phillipson, C. (1999) The Social Construction of Retirement: Perspectives from Critical Theory and Political Economy. In: Minkler, M. and Estes, C., Eds., Critical Gerontology. Perspectives from Political and Moral Economy, Baywood, New York.

[14] Del Valle, T. (1997) La memoria del cuerpo. Review of ARENAL, 4, 59-74.

[15] Osorio, P., Torrejón, M.J., Meersohn, C. and Anigstein, M.S. (2011) Comprensión de la calidad de vida en personas mayores semivalentes en Chile. Salud \& Sociedad, 2, 203-217. 